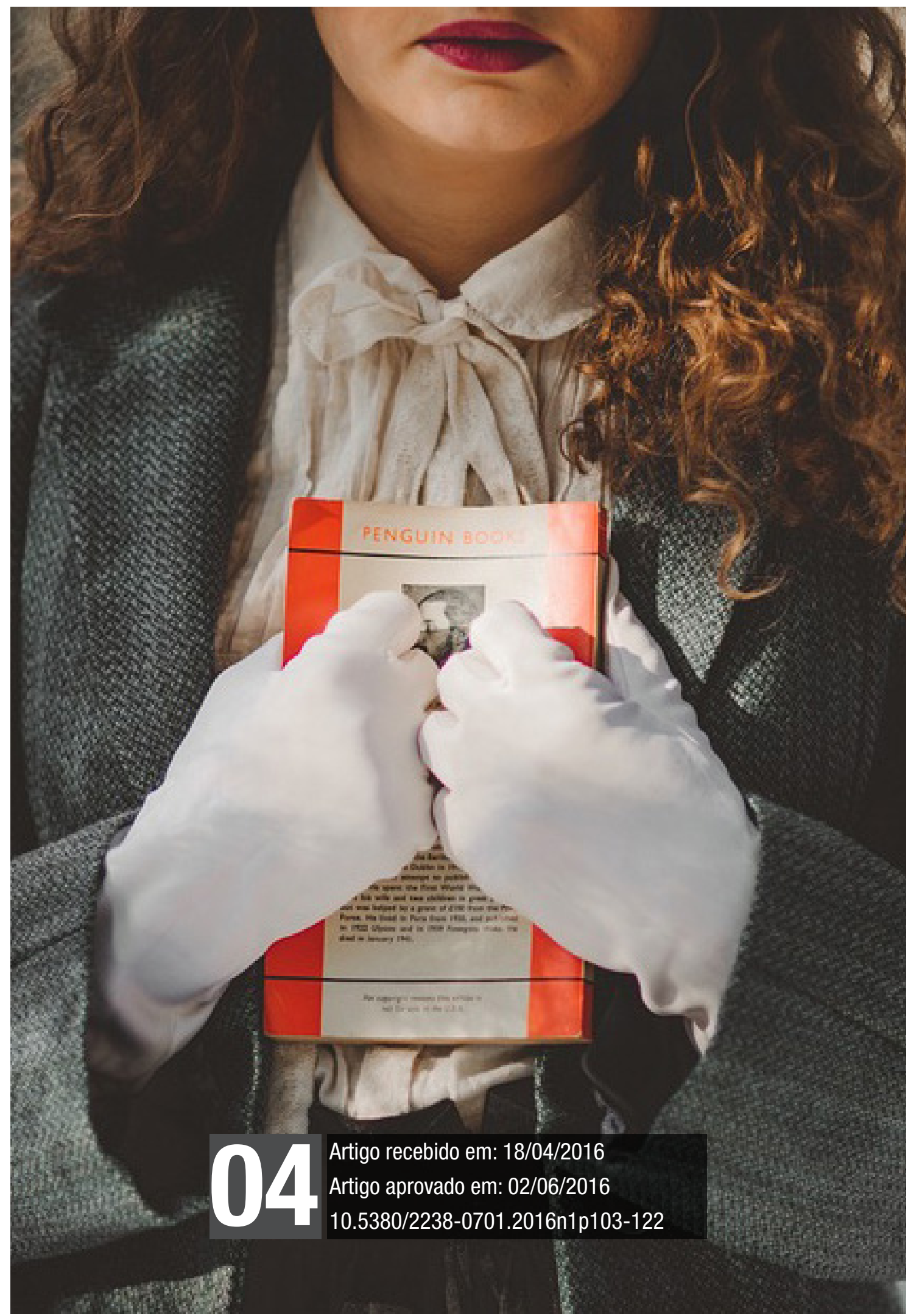


Lectura. Autoayuda. Representaciones sociales.

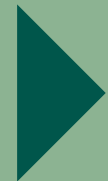




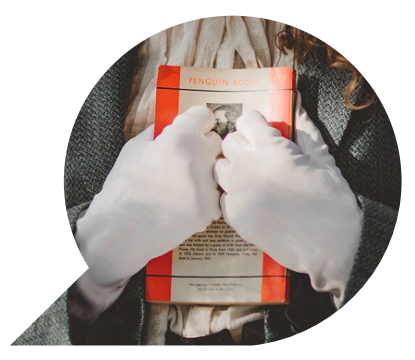

\title{
Redescubriendo el valor simbólico del consumo de literatura: el caso de lectores $y$ libros de autoayuda en Argentina
}

\author{
Redescobrindo o valor simbólico do \\ consumo de literatura: o caso dos leitores \\ e livros de autoajuda na Argentina \\ Rediscovering the symbolic value of \\ consumption of literature: the case of \\ readers and self-help books in Argentina
}

\section{VANINA BELÉN CANAVIRE *}

Resumen: Teniendo en cuenta que construir un público es una de las operaciones más complicadas de la cultura contemporánea, existe algo que diferencia a la literatura de autoayuda de otros productos de consumo masivo, cuestión que se refleja en la posición privilegiada que ésta ostenta en el mercado editorial actual. A partir de ello, en este artículo, reflexionamos a propósito de las representaciones que los propios lectores realizan sobre la lectura de autoayuda, atendiendo a la disposición personal y física que los individuos invierten en esta práctica, los escenarios de lectura, y

\footnotetext{
* Doutora em Estudos Sociais da América Latina pelo Centro de Estudios Avanzados de la Universidad Nacional de Córdoba. Jornalista pela Universidad Nacional de Jujuy (UNJu). Docente e investigadora da UNJu e bolsista Pos-doutoral do CONICET. E-mail: belencanavire@hotmail.com
} 
las circunstancias biográficas en que se desarrolla la actividad lectora. Concluimos en que, asignarle a la lectura de autoayuda una función instrumental por excelencia, no deja ver el valor simbólico que esta práctica adquiere en la vida cotidiana: se trata de una lectura que también construye, llena vacíos, repara.

Palabras clave: Lectura; Autoayuda; Representaciones sociales, Placer; Subjetividad.

Resumo: Dado que construir uma audiência é uma das operações mais complicadas da cultura contemporânea, algo diferencia a literatura de autoajuda de outros produtos da cultura de massa, reflexo da posição privilegiada que detém no atual mercado editorial. A partir disso, neste artigo vamos refletir sobre as representações que os leitores constroem sobre a leitura de autoajuda, atendendo à disposição pessoal e física que indivíduos investem nessa prática, cenários de leitura e as circunstâncias biográficas onde a atividade de leitura se desenvolve. Conclui-se que, atribuir à leitura de autoajuda uma função instrumental, obscurece o valor simbólico que esta prática possui na vida cotidiana: é uma leitura que também constrói, preenche lacunas, repara.

Palavras-chave: Leitura; Autoajuda; Representações sociais, Prazer; Subjetividade.

Abstract: Given that build an audience is one of the most complicated operations of contemporary culture, there is something that differentiates self-help literature of other consumer products, an issue that is reflected in the privileged position it holds in the publishing market current. From this, in this article we reflect about the representations that readers make about reading selfhelp, attending to personal and physical disposition that individuals invest in this practice, scenarios reading, and biographical circumstances where the reading activity develops. We conclude that, assign reading self-help an instrumental role par excellence, obscures the symbolic value that this practice takes in everyday life: it is a reading that also builds, fills gaps, repairs.

Key words: Reading; Self-help; Social representations; Pleasure; Subjectivity. 


\section{Introducción}

Teniendo en cuenta que la cultura es comprensible a partir del estudio de sus componentes simbólicos, en nuestra tesis de doctorado (CANAVIRE, 2013) indagamos en una práctica cultural cuyo interés se renueva incesantemente resistiendo a los avatares del tiempo: la lectura. Acotamos el estudio a un género de la cultura de masas que ostenta una imponente presencia en el mercado editorial actual: la literatura de autoayuda ${ }^{1}$, e intentamos responder a los siguientes interrogantes: ¿Qué mueve a una persona a consumir libros de autoayuda? ¿Por qué gustan? ¿Por qué se compran? ¿Por qué se leen?

La comunicación como estrategia analítica nos permitió posicionar la mirada desde el vértice de la recepción. Asimismo, privilegiamos la concepción de la lectura como invención de sentido (siempre inscrita en las restricciones y limitaciones que impone el texto) y como práctica social (inserta en un entramado de posiciones y relaciones diferenciadas) en el marco de circunstancias espacio-temporales específicas. Desde esa perspectiva, acotamos el campo de estudio a un caso: lectores de autoayuda en San Salvador de Jujuy (Argentina) ${ }^{2}$.

A partir de ello, en este artículo, reflexionamos a propósito de las representaciones sobre la lectura que construyen los propios lectores. Así, textos que, desde la comunidad académica y la crítica literaria, se asocian a lecturas "de distracción", desde la perspectiva del lector, pueden vincularse a lecturas "placenteras", "creativas", o "reparadoras". Reconocemos, entonces, el papel simbólico de la lectura de autoayuda.

\footnotetext{
${ }^{1}$ En Brasil, según el informe del Instituto Pró-Livro desarrollado en el período junio-julio del año 2011, en la lista de los "géneros leídos frecuentemente", la literatura de autoayuda se ubica en el sexto lugar. Así también, entre los 25 libros más destacados para el mismo período, figuran $O$ alquimista (COELHO, P., 2008), $O$ segredo (BYRNE, R., 2007) y $O$ monge e o executivo (HUNTER, J., 2004). En Colombia, según los registros de la Librería Nacional, Los Cuatro Acuerdos (RUIZ, M., 1998) y Descubre tu Don (SHAJEN, J., 2011) figuran entre los más vendidos. En México, Los 7 hábitos de la gente altamente efectiva (COVEY, S., 2010) se ubica entre las primeras posiciones. Mientras que, en España, El secreto (BYRNE, R., 2007) se encuentra en el ranking de los más solicitados. A nivel local, según los registros del Grupo ILHSA (líder en la venta de libros en Argentina) tres de los diez libros más vendidos en el año 2011 pertenecen al género de autoayuda: Corriéndose al interior (PALUCH, A., 2011); Lecciones de Seducción (SORDO, P., 2010); Sé tu propio héroe (DOMÍNGUEZ, C., 2011). Datos disponibles en: <http://www.prolivro.org.br/ipl/ publier4.0/dados/anexos/2834_10.pdf ; http://www.librerianacional.com/es/index.php?option=com_catalogo\&idCategoria=287; http://www.gandhi.com.mx/ ; http://www.casadellibro. com/; http://www.tematika.com/libros/>.

${ }^{2}$ Jujuy - San Salvador es su capital - es una de las provincias fundacionales de la República Argentina, situada en el extremo Norte limita con los países de Bolivia y Chile. En cuanto a su dimensión territorial es una de las más pequeñas del suelo argentino.
} 


\section{Notas metodológicas}

El marco metodológico que ha orientado nuestra investigación se nutre fundamentalmente de dos propuestas teórico-metodológicas. Por un lado, recurrimos a las reflexiones que desarrolla Thompson (2006) a propósito del análisis de las formas simbólicas ${ }^{3}$ en general y las formas simbólicas massmediadas en particular. Por otro, retomamos las cuestiones metodológicas que señala Reguillo (2000) respecto del orden del discurso ${ }^{4}$ como mediación analítica para la comprensión de la vida social.

Ambas propuestas metodológicas tienen como telón de fondo la necesidad de comprender cuál es el papel del sujeto en la construcción de lo social. A pesar de que los investigadores provienen de diferentes disciplinas (sociología y comunicación respectivamente), ambos se apoyan principalmente en las ideas planteadas por la "hermenéutica", de allí que otorguen particular relevancia a la experiencia del actor social como lugar privilegiado para el análisis y la comprensión de la vida social.

Asimismo, teniendo en cuenta que sólo a través del discurso los sujetos son capaces de referirse subjetivamente al mundo, ambos autores comparten la preocupación por la apropiación e interpretación que realizan los actores sociales en condiciones particulares. Si se considera que el sentido es una facultad del actor histórica y socialmente situado, es precisamente en el discurso donde se pueden hallar los distintos filtros y mediaciones (más importantes que

\footnotetext{
3 "Las formas simbólicas (entre las que se incluyen acciones, enunciados y objetos de diversos tipos) son constructos significativos que son interpretados y comprendidos por los individuos que los producen y reciben, pero también son constructos significativos que se estructuran de maneras diferentes y que se insertan en condiciones sociales e históricas específicas" (THOMPSON, 2006, p. 407).

${ }^{4}$ Reguillo advierte que entre a) el orden institucionalizado del discurso (formación discursiva) y b) la práctica discursiva de los actores (plano del relato/narrativas), existen mediaciones fundamentales operadas por las condiciones de producción del discurso (el campo discursivo de lo religioso, de lo político, de lo educativo, de lo cultural) así como por la posición diferencial de los actores implicados en una práctica discursiva (estrategias discursivas) (2000, p. 53).

${ }^{5}$ Thompson ofrece una breve reseña de las principales ideas propuestas por los filósofos hermenéuticos de los siglos XIX y XX: "el estudio de las formas simbólicas es fundamental e inevitablemente una cuestión de comprensión e interpretación"; "el objeto de nuestras investigaciones es en sí mismo un campo preinterpretado"; "los sujetos que constituyen el campo sujeto-objeto son, como los propios analistas sociales, sujetos capaces de comprender, reflexionar y actuar a partir de esta comprensión y reflexión"; "los sujetos se insertan siempre en tradiciones históricas" (2006, p. 398-401). Son los trabajos de Dilthey, Heidegger, Gadamer y Ricoeur, los que tienen una relevancia particular para sus preocupaciones.
} 
el decir mismo) que constituyen los anclajes desde los cuales éste construye el sentido sobre el mundo.

Por último, creemos que ambas propuestas metodológicas intenta comprender a los actores en su contexto y se ofrecen como estímulo para la investigación empírica (es decir, se destinan a una aplicación en casos concretos), y por esto, resultan apropiadas para aquellos estudios que se ocupan especialmente de procesos y actividades que integran la vida cotidiana de los sujetos. En este sentido, estimamos que pueden servir ampliamente a investigaciones desarrolladas en el ámbito de la comunicación y la cultura.

En el caso de nuestro estudio, la investigación tuvo lugar en San Salvador de Jujuy, capital de Jujuy. Esta ciudad es la más poblada de la provincia, y constituye su centro político-administrativo y comercial. A partir de un recorrido exploratorio, observamos que la literatura de autoayuda ostenta un lugar de privilegio en las principales librerías de este espacio urbano, lo que resultó significativo para dilucidad la problemática que nos ocupa.

El proceso de indagación se realizó mediante entrevistas en profundidad. Para elaborar la muestra del estudio, se tomaron en consideración características sociodemográficas y de consumo. Los criterios de selección de los informantes fueron: a) residir en la ciudad de San Salvador de Jujuy, b) pertenecer a una franja etaria específica (entre 25 y 55 años de edad), c) haber leído como mínimo cinco libros de autoayuda en el transcurso de los últimos dos años (bienio 2010-2011) . $^{\circ}$

La búsqueda de los informantes se desarrolló de dos maneras. Por un lado, en el trabajo de campo, registramos a los clientes que ingresaban en las librerías locales en busca de libros de autoayuda, específicamente. Por otro lado, teniendo en cuenta los nuevos dispositivos de comunicación (chats, SMS, foros y redes sociales) no sólo como ambientes virtuales de interacción social, sino, también como "base de datos", empleamos un recurso online: la red social Facebook. De esta forma, siguiendo los criterios de selección definidos para la investigación, contactamos a los usuarios que mencionaban en su página de perfil, como "libros preferidos" a ejemplares del género de autoayuda. Finalmente, la muestra se compuso de 50 lectores (25 mujeres y 25 hombres).

${ }^{6}$ Cabe destacar que el trabajo de campo fue desarrollado en el año 2012. 
Una vez seleccionados los lectores, las entrevistas en profundidad fueron realizadas de forma personal y presencial. Este universo de estudio, tuvo como marco de referencia el "muestreo teórico" y "la saturación de datos” (GLASER Y STRAUSS, 2008).

\section{El papel simbólico de la lectura de autoayuda}

Un libro leído está en función de quien lo lee, y lo que determina la cualidad del lector, no es sólo qué o cuánto lee, sino la manera en que capitaliza la lectura en las distintas esferas de su vida. En este sentido, entendemos que la práctica lectora, puede ser densa por los usos que produce en los diferentes contextos en los que se inserta.

Esto implica que el análisis sobre las "representaciones de la lectura", requiere tener en cuenta distintos elementos: la disposición personal y física que los individuos invierten en esta práctica; los "escenarios de lectura"; y las circunstancias biográficas en que se desarolla la actividad lectora.

Pues bien, a partir de las definiciones ofrecidas por nuestros interlocutores, intentamos reconocer el papel simbólico de la lectura de autoayuda, sin olvidar, claro, las múltiples imbricaciones que tienen lugar en el mismo proceso lector.

\section{Lecturas placenteras}

Sobre la cuestión del placer (psíquico), Ansermet y Magistretti advierten: "el placer es lo más subjetivo que existe. Lo que es placer para uno no lo es para otro. No hay receta para el placer" (ANSERMET y MAGISTRETTI, 2012, p. 15). Esto anticipa que la cuestión del placer puede resultar ambigua, e incluso enigmática. En vista de ello, no sorprende la pluralidad de sentidos que los lectores adscriben al término "placer".

Placer y emoción

La lectura, en no pocas ocasiones, se representa como una experiencia sensual, que se experimenta en el cuerpo.

\footnotetext{
${ }^{7}$ Entendemos, con Bahloul, al "escenario de lectura" como el "conjunto de las condiciones sociales producto de la historia familiar, socio-profesional y educativa de los lectores" (2002, p. 23).
} 
Como sucede en el caso de Viviana:

Me resulta muy placentera la lectura, depende de cómo me sienta... a veces agarrar uno de estos libros hace que mis 24 horas sean 'fabulosas'. Generan muchas emociones... arrepentimientos. Te reís de vos mismo, o llorás muchas veces porque destapás cosas muy ocultas" (Viviana, 40 años, nutricionista).

Asistimos, entonces, a una lectura que deleita y conmueve. En este sentido, es posible encontrar placer en el sonido de las palabras, cuando éstas movilizan la intuición, las emociones y las sensaciones corporales. Para que afloren los sentimientos, se trata de lecturas perturbadoras, estimulantes, que le hablan personalmente al lector, en sus circunstancias particulares. Por lo tanto, leer no implica solamente comprender sino también experimentar sensaciones, revivir emociones, verse afectado por el libro. Esta relación íntima que se establece entre lector y texto, es la que permite que los lectores compartan (o se identifiquen con) las alegrías y aflicciones de los personajes de las narraciones presentadas en los textos "como si" fueran propias: lectores que se abandonan a las sensaciones, lectores sensibles.

\section{Placer y libertad}

Indudablemente, el placer también aparece ligado al sentimiento de libertad. A esto refiere Alejandra cuando señala: "antes he leído algunas cosas por obligación, ahora, después de mi grave enfermedad, leo por placer, leo lo que quiero, cuándo quiero y cómo quiero" (Alejandra, 54 años, psicóloga).

$\mathrm{Si}$, como sostiene Fernando Savater "el mundo de la lectura es un mundo de la libertad” (SAVATER, 2009, p. 336), la relación íntima que se entabla entre lector y escritor es una relación liberadora y profundamente placentera. En este sentido, la lectura de autoayuda se describe como una lectura "libre", en oposición a otras lecturas "obligadas". Ahora bien, la libertad del lector se expresa en distintos momentos de la práctica lectora. En principio, se manifiesta a la hora de elegir cuáles libros leer, y en la decisión de asignar un tiempo específico a esta actividad en el trajín diario. Asimismo, el lector es libre cuando hace recorridos laberínticos por el texto, saltea capítulos, y abandona o retoma la lectura. $\mathrm{Y}$, sobre todo, se trata de una forma de liberación, cuando el lector descubre el chispazo de lo que puede 
producir un texto, cuando puede cambiar de rumbo después del encuentro con un libro.

\section{Placer y aprendizaje}

Otros lectores dan cuenta de un placer intelectual. Así, lo expresa Marcos: "leo libros de autoayuda por el placer que me da aprender y seguir buscando respuestas. Además, es algo intelectual porque encuentro vocabulario, temas y definiciones que no conozco" (Marcos, 37 años, odontólogo).

El libro es, fundamentalmente, un medio de acceso al saber, por ello no sorprende que el placer de la lectura se vincule también a la posibilidad de ampliar conocimientos. De allí que la lectura, no sólo contribuye al enriquecimiento intelectual, sino que también puede volver al lector más libre y consciente de su actuar.

En el mismo orden de ideas, Eugenia comenta:

Leo por placer, me parece que es algo que me ayuda a estar más preparada para la vida. Cuando mis hijos eran pequeños, he leído a Barylko, que es un psicólogo en niños y adolescentes, y me ayudó en la crianza de los chicos. Me parece que todo lo que vos leés te aporta, aunque no esté clasificado dentro de la enseñanza formal (Eugenia, 42 años, contadora).

La lectura, en general, y la de autoayuda, en particular, se vinculan a los aprendizajes funcionales inducidos por las necesidades de la vida cotidiana. De allí se explica que el lector valore los conocimientos prácticos que ofrecen los libros de autoayuda, más allá de los cánones establecidos por la institución educativa o literaria. En efecto, los lectores no establecen una oposición entre una lectura instructiva y una lectura de esparcimiento, sino que la lectura de autoayuda se representa como una lectura de placer y de aprendizaje a la vez.

\section{Placer y enriquecimiento espiritual}

Kafka escribió en 1904, "creo que sólo debemos leer libros que nos muerdan y nos arañen. Si el libro que estamos leyendo no nos obliga a despertarnos como un mazazo en el cráneo ¿para qué molestarnos en leerlo?" (KAFKA, citado en MANGUEL, 1998, p. 116). 
De esta manera, se recomendaban lecturas que afecten y movilicen al lector, que lo golpeen.

Pues bien, hemos identificado lectores que también asocian el placer de la lectura con una experiencia de ruptura, con un quiebre subjetivo (necesario para el "crecimiento espiritual").

En principio, Cintia reconoce: "leo por placer, pero dentro del placer ésto me suma, me es útil para todo, para sumar optimismo. Son libros de crecimiento emocional, y de hecho, son básicos, pero lo básico no significa que no sirva" (Cintia, 45 años, artista plástica).

Como hemos señalado, los libros de autoayuda ofrecen pautas de acción que - si se ponen en práctica - permitirían al lector liberarse de los "miedos internos", y en este sentido, ofrecen certidumbres, esperanza. De allí que más allá de la estilística del género, el valor personal que se asigna a la lectura reside en que se inscribe en la esfera del crecimiento espiritual. Así pues, en la práctica lectora, se conjugan placer y "autorrealización".

En la misma línea de pensamiento, Julieta menciona: "leo por placer, por enriquecerme y llegar a la iluminación. De acuerdo a cómo leas los libros, pueden enriquecerte y quedarse en vos para siempre" (Julieta, 32 años, profesora de danzas).

De esta manera, se repite la idea de una lectura que permite evolucionar, la "receta de la felicidad" se torna, entonces, una cuestión de actitud y de predisposición hacia el cambio (de pensamiento, de conducta, etc.). Asimismo, la lectura, antes que describirse como un placer momentáneo, se representa como una experiencia perdurable para la memoria y el cuerpo.

De forma similar, Alba manifiesta: "estos libros nos llevan a reflexionar para sentirnos mejor con nosotros mismos... no son para nada un pasatiempo, a mí leer me da placer, me llena el alma" (Alba, 39 años, comerciante).

Los pensamientos que dispara la lectura de autoayuda, también pueden llevar a un entendimiento de sí mismo, del otro, del mundo. De allí que no se considere una actividad de entretenimiento como cualquier otra, por el contrario, se concibe como una práctica esencial para el desarrollo personal. La lectura es placentera porque arrebata los sentidos, y transporta al lector hacia el "mundo interior". Se puede hablar, entonces, de una lectura que "multiplica el alma, sus vértigos y sus posibilidades” (SAVATER, 2009, p. 337). 
El "entretenimiento" es un modo posible de definir al "placer". Por ello, no sorprende que se subraye a la práctica lectora como una forma de esparcimiento.

Al respecto, Denise evoca: "son una lectura de color, pasa por una cuestión de modificar lo 'pesado' que vengo leyendo. Diría que leo por entretenimiento” (Denise, 28 años, estudiante).

Mientras que Jaime expresa: "leo por entretenimiento. Me gusta mucho leer cosas técnicas, y como estos libros están al borde de eso me entretienen, aunque luego sean prácticos" (Jaime, 35 años, profesor universitario).

De esta manera, las lecturas de autoayuda se conciben como un pasatiempo (en cuanto permiten hacer más llevadera otra cosa) que recrea el ánimo del lector. Desde luego, a pesar de que no se le asigne un estatuto de excepción en relación a los hábitos lectores, esto no implica que la lectura de autoayuda se encuentre desprovista de valor, es decir, continúa siendo definida por las competencias culturales del lector y sometida a las intermitencias de deseos y necesidades personales.

Así también, en la opinión de Beatriz, el placer aparece vinculado a la diversión: "no hay manera de leer obligado... salvo que forme parte de los estudios. Leer es uno de los momentos placenteros que se tienen, y estos en particular (los de autoayuda) me parecen libros divertidos" (Beatriz, 40 años, abogada).

Cuando el placer de la lectura connota esparcimiento o distracción, puede vincularse incluso al placer lúdico. En estos términos, el libro representa un objeto de placer como cualquier otro, por lo que la lectura se incorpora a los placeres de la vida, se anota en el catálogo personal de las sensualidades. Es justamente de este acercamiento entre los "goces" de la vida y los del texto, del que habla Barthes cuando propone "abolir la falsa oposición entre vida práctica y vida contemplativa” (BARTHES, 2011, p. 77).

\section{Lecturas creativas}

El acto de lectura, explica Roger Chartier, no puede ser anulado en el texto mismo, en tanto, las prácticas que se captan siempre son creadoras de usos o de representaciones que no pueden reducirse a

\footnotetext{
${ }^{8}$ Según el Diccionario de la Real Academia Española. Entrada: "placer".
} 
las voluntades de los productores de discursos y de normas. De esta forma, "la aceptación de los mensajes y de los modelos siempre se realiza a través de arreglos, de desvíos y de nuevos empleos singulares" (CHARTIER, 1994, p. 54). A propósito de esto, Valeria nos habla sobre su modalidad de lectura:

Leer un libro es situarse en el estado mental del escritor, y aprender un poco de sus experiencias, su lógica, y la manera en que entiende la filosofía de vida. En la vorágine de las actividades diarias, leer estos libros hace repensar algunos temas de modo sencillo... hay libros que están destinados a incorporarse a uno, y otros que no (Valeria, 35 años, empleada estatal).

Mientras que, desde una postura más crítica, Julieta señala:

A veces no coincido con las opiniones del autor. No soy pasiva en la lectura, de algún modo 'converso' con los libros. Los que siempre vuelvo a consultar son La Inteligencia emocional ${ }^{9}$, El arte de la felicidad $^{10}$, Tú también puedes ser budista ${ }^{11} \ldots$ por ahí memorizo alguna frase, es positivo que recuerdes una imagen o una cita para mantenerte tranquila (Julieta, 32 años, profesora de danzas).

En una obra literaria, el autor trata de comunicar sensaciones, emociones e ideas: su sentido de la vida. En efecto, la experiencia literaria reside en esa "transacción" dinámica entre la obra y lo que el lector ya conoce, siente o desea.

Ahora bien, en el caso de la lectura de autoayuda, esta "transacción" propicia diferentes situaciones. Por un lado, habrá lectores que hagan un esfuerzo particular por acortar las distancias entre su propio punto de vista y el del autor. Por otro, habrá quienes interpelen al texto desde una postura más crítica, que puede girar en torno al "alcance generalista" o "ambigüedad" de las propuestas textuales. Así también, el lector puede llevar a cabo operaciones imprevistas, como hurtar fragmentos y memorizarlos: capitaliza los conocimientos que le resultan útiles. En vista de ello, los usos que se hacen del texto dan cuenta de una manera de leer, de "tácticas"12 diferenciadas y creativas mediante las cuales es posible interpelar al material impreso.

${ }^{9}$ GOLEMAN, Daniel. La inteligencia emocional. Buenos Aires: Vergara, 2000.

${ }^{10}$ CUTLER, Howard. Dalai Lama. El arte de la felicidad. Barcelona: Debolsillo, 2010.

${ }^{11}$ KHYENTSE, Jamyang. Tú también puedes ser budista. Barcelona: Kairós, 2008.

${ }^{12}$ La expresión que tomamos de Certeau (2007) nos resulta oportuna para señalar que el mensaje no se impone en la mente del lector, sino que en la recepción siempre hay distorsión, resistencia, desviación. 
No obstante, e indistintamente del trabajo lector, en la mayoría de los casos, la experiencia lectora de autoayuda se representa fundamentalmente como una pausa que permite meditar sobre el propio modo de ser y reflexionar sobre las situaciones conflictivas.

\section{Lecturas prácticas}

La lectura también puede concebirse en términos esencialmente instrumentales. A continuación, evocamos a lectores que destacan la dimensión utilitaria de la literatura de autoayuda.

Como nos lo recuerda Alba:

Las lecturas son prácticas en tanto yo quiera que sean prácticas. Creo que depende del momento en que uno lee el libro, porque me va a servir de acuerdo a la apertura que yo tenga en ese momento. Siempre los vuelvo a consultar, a medida que vamos creciendo espiritualmente valoramos más el libro y descubrimos cosas que no vimos antes (Alba, 39 años, comerciante).

En el mismo orden de ideas, Analía indica:

Todo lo que vos leés lo tenés que poner en práctica, más si estás en un camino de 'crecimiento'. El de Krishnamurti ${ }^{13}$, por ejemplo, es un libro que necesitas releer, hoy leés una página y la reflexionás... y recién mañana podés continuar, no lo podés devorar. La relectura me sirve para hacer nuevos subrayados de acuerdo a lo que me está pasando en ese momento (Analía, 38, diseñadora gráfica).

En el circuito vivo que se establece entre lector y texto, es el lector quien infunde significados intelectuales y emocionales a los símbolos verbales. De allí que la puesta en práctica de las pautas de acción y subjetivación ofrecidas en los textos, se relaciona directamente con la postura intelectual que asuma el lector (su "apertura mental") y con sus necesidades y preocupaciones específicas. Asistimos, entonces, a la representación de la lectura no sólo en términos de una operación intelectual, sino también emocional y sentimental.

Pues bien, la utilidad de la lectura reside en traducir los consejos de autoayuda a cuestiones prácticas. El lector se apropia de las instrucciones que halla en los textos, y las adapta a sus circunstancias y ámbitos de acción particulares. De este modo, las consignas de los

${ }^{13}$ La lectora hace referencia a Krishnamurti, Jiddu. La libertad interior. Barcelona: Kairós, 1996. 
libros pasan a formar parte de las experiencias cotidianas del lector. En efecto, son distintos los desplazamientos que propicia la lectura de autoayuda: entenderse mejor a sí mismo, aprender a controlar las emociones, liberarse de las dudas o ansiedades personales, etc.

La apropiación lectora varía según las aptitudes y necesidades de cada lector, pero también está estrechamente relacionada al contexto espacio-temporal en el que surge y cobra sentido. Es así que, de acuerdo a la situación y momento de la vida en que se lleve a cabo el ejercicio de relectura, éste puede entrañar la posibilidad de abrir el sentido de los textos, formular nuevas interpretaciones, y ampliar los conocimientos.

De esta manera, una actividad que suele quedar relegada al plano cognitivo, ahora encuentra anclaje en el campo empírico: el valor de la lectura de autoayuda reside en la aplicación práctica de las enseñanzas de los libros. Se revela, de este modo, el intento de los lectores de acercar los libros a la vida, de volver prácticas y reales esas concepciones (las de los textos) que empiezan a ser suyas.

\section{Lecturas reparadoras}

Frente a necesidades vitales y existenciales, los libros de autoayuda pueden constituir una válvula de escape a las carencias sentidas en las distintas esferas de la vida: los lectores coinciden en que es posible "descubrirse" o "(re)construirse" a través de la lectura.

A propósito de esto, Fabricio expresa: "desde mi ego, acudir a estos libros era una muestra de debilidad, pero la lectura me ayudaba a resolver mis problemas... en ese momento yo no me 'soportaba' a mí mismo, las cosas eran como una tormenta en mi cabeza" (Fabricio, ingeniero electrónico, 43 años).

Por su lado, Cecilia manifiesta:

Soy católica pero no practico, y no creo completamente en la idea de "la vida después de la muerte". Cuando perdí a mi papá, era un dolor tan grande que busqué ayuda en mi psicólogo, en estos libros, en la Iglesia. Uno busca respuestas por todos lados ¿no? y leerlos varias veces me causaba alivio (Cecilia, ama de casa, 40 años).

De este modo, en los momentos de desastres íntimos, los libros de autoayuda parecieran "llegar al rescate". Como es sabido, las crisis emocionales afectan el sentimiento de continuidad propia y la autoestima: el "mundo interior" se desmorona. En tales circunstancias, la 
lectura puede ir más allá del olvido momentáneo de las penas, tiene que ver con la voluntad de hacerse cargo de sí mismo, con la recomposición de la imagen de sí. En este sentido, puede representar una vía de acceso privilegiada para sostener el sentimiento de individualidad y resistir a las adversidades.

En situaciones límites, cuando se enfrentan los temores más íntimos, habrá personas que busquen respuestas en la fe religiosa, el consejo psicológico, o en la consulta de lo escrito. Así pues, la lectura, en tanto abre un camino hacia la interioridad, se consolida como otra posibilidad para reconstruirse en momentos críticos. Ahora, si bien la "Palabra de Dios", la palabra terapéutica, y el discurso de autoayuda, pertenecen a distintas esferas de conocimiento, tienen un denominador común: demandan una entrega del sujeto hacia lo que lee (o escucha), porque sin entrega no hay reconstrucción posible.

Asimismo, la eficacia de los libros de autoayuda tiene que ver con que una vez leídos no quedan inmediata y definitivamente guardados en la biblioteca: la función reparadora no se agota en la primera lectura, sino que se prolonga en posteriores relecturas.

De este forma, se advierte que asignarle a la lectura de autoayuda una función instrumental por excelencia, no deja ver el hecho de que esta lectura también construye, llena vacíos, edifica.

\section{Cartografía de la comprensión lectora}

Atendiendo a la historia de la lectura, la abundancia de lecturas fue considerada peligrosa y perniciosa durante mucho tiempo justamente por la libertad individual frente al libro: por el "placer" de leer ${ }^{14}$.

En los casos estudiados, está claro que no se trata del placer estético que se halla en las obras de arte o de "alta literatura", sin embargo, los lectores encuentran un modo de definir al placer en sus propios términos, diferentes a los de la comunidad intelectual o la crítica literaria, pero no por ello de menor valor: la lectura de autoayuda se carga de valor simbólico, se manifiesta como una práctica con su propia lógica.

Según las circunstancias, el estado de ánimo y los recuerdos, las experiencias y los deseos, el placer en la lectura se representa de distintos modos. Asistimos, entonces, a una lectura de distracción, de

\footnotetext{
${ }^{14}$ Una síntesis de las razones por las que propietarios de esclavos y dictadores temían al poder de la lectura, puede leerse en Manguel (1998), especialmente el apartado "Lecturas prohibidas".
} 
entretenimiento, de goce. Una lectura que afecta, que conmueve, que "golpea". Una lectura sensual, que moviliza emociones y sensaciones corporales. Una lectura libre (que se realiza por elección propia) y liberadora (cuando un libro modifica la trayectoria del lector). Una lectura instructiva que acrecienta el bagaje cultural y "prepara" para la vida. Una lectura enriquecedora que propicia el entendimiento de sí mismo y de los otros.

Ahora bien, los libros no sólo procuran el placer del momento, sino que entre texto y lector se entabla otro tipo de relación, donde las palabras perduran en la memoria y el cuerpo: la lectura se mezcla con la experiencia, busca emociones, sentimientos, formas corporales.

Teniendo en cuenta la dialéctica entre la coacción ejercida por los textos y la inventiva del público, el análisis precedente da cuenta de una postura activa del lector. El lector no siempre está de acuerdo con lo que propone el texto, no sigue las instrucciones al pie de la letra, ni adopta los consejos sin previa reflexión. Este gesto de transgresión, se representa como una lectura crítica, y forma parte de los mecanismos habituales de lectura.

Además, al ejercicio reflexivo de la lectura, le continúa la puesta en práctica de los conocimientos aprehendidos. El lector extrae del texto los preceptos que le resultan útiles, los matiza con su experiencia y los adapta a sus circunstancias biográficas. El valor de la lectura reside en traducir los consejos de autoayuda a cuestiones de la vida cotidiana, son lecturas prácticas.

En numerosas ocasiones, la lectura ayuda a personas en crisis. La literatura de autoayuda puede afectar la vida del lector y ejercer una función reparadora. En tal sentido, impide que éste se detenga inmovilizado por la decepción o el fracaso, alivia las angustias personales, o alienta a la reconstrucción de la imagen de sí. La lectura, de algún modo, parece dar forma a lo caótico.

A menudo, la eficacia de los textos se relaciona al hecho de que luego de la lectura inicial no quedan inmediata y definitivamente guardados en la biblioteca, por el contrario, ante una situación crítica o desequilibrante, el lector puede recurrir nuevamente a los libros en búsqueda de respuestas. El ejercicio de relectura permite hallar nuevos sentidos o hacer nuevos subrayados, en función de las circunstancias biográficas que se atraviesen: el texto se actualiza en virtud de las circunstancias particulares del lector. De este modo, leer un libro de autoayuda es una actividad programada como lectura per se, pero 
luego, en la relectura, puede adquirir un carácter puntual y circunstancial de práctica consultiva.

Allí donde los críticos suele advertir una "moda", un "fenómeno de masas" o un "boom del mercado", hemos visto que el lector, por su parte, lleva adelante una empresa compleja: lee, reflexiona, reformula y pone en práctica. Este hecho sólo es posible porque cree en lo que lee ${ }^{15}$, entonces, no se trataría de un lector displicente o superficial, sino que se esboza un "lector creyente". Un lector que bucea estratégicamente en los textos, buscando ese fragmento, esa frase, esa palabra que, sino transforma, cuanto menos sosiegue el devenir agitado de su existencia.

\section{REFERENNCIAS}

ANSERMET, François; MAGISTRETTI, Pierre. Los enigmas del placer. Buenos Aires: Katz, 2012.

BAHLOUL, Joelle. Lecturas precarias. México: Fondo de Cultura Económica, 2002.

BARTHES, Roland. El placer del texto y Lección inaugural. Buenos Aires: Siglo XXI, 2011.

CANAVIRE, Vanina. Cuando leer llena el alma: representaciones, funciones y efectos de la lectura de autoayuda: el caso de lectores en San Salvador de Jujuy. Tesis doctoral, Centro de Estudios Avanzados, Universidad Nacional de Córdoba, Córdoba, Argentina, 2013.

CERTEAU, Michel de. La invención de lo cotidiano. v. I Artes de hacer. México: Universidad Iberoamericana, 2007.

CHARTIER, Roger. Lecturas y Lectores en la Francia del Antiguo Régimen. México: Instituto Mora, 1994.

DICCIONARIO DE LA REAL ACADEMIA ESPAÑOLA. Disponible en

15 La idea de que en la escritura está depositada la verdad, es un saber muy antiguo que cruza la cultura letrada y obliga a leer para saber la verdadera razón de las cosas (todo aquello que se puede leer es creíble, desde lo bíblico hasta el saber académico). 
$<$ http://www.rae.es/rae.html $>$.

MANGUEL, Alberto. Una historia de la lectura. Madrid: Alianza Editorial, 1998.

REGUILLO, Rossana. Anclajes y mediaciones del sentido. Lo subjetivo y el orden del discurso: un debate cualitativo. Revista Universidad de Guadalajara, $n^{\circ} 17,2000$, p. 50-55.

SAVATER, Fernando. Agonía y resurrección del libro. En: AA.VV. Congreso Internacional del Mundo del Libro. México: FCE, 2009, p. $327-$ 338.

THOMPSON, John. Ideología y cultura moderna. Teoría crítica social en la era de la comunicación de masas. México: Universidad Autónoma Metropolitana, 2006. 
AÇÃO MIDIÁTICA, n.11. Jan/jun. 2016. Curitiba. PPGCOM-UFPR. ISSN 2238-0701

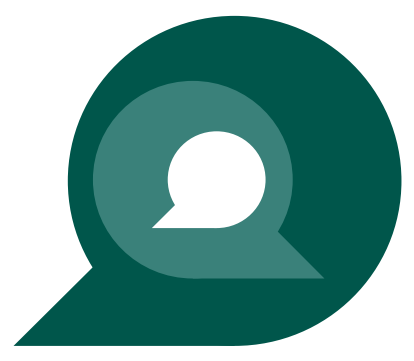

